\title{
DEMANDAS E AGENDAS DA PESQUISA EM EDUCAÇÃO AMBIENTAL NO BRASIL: SENTIDOS CONSTRUIIDOS A PARTIR DOS RELATOS DOS GRUPOS DE DISCUSSÃO DE PESQUISA EM EDUCAÇÃO AMBIENTAL (GDPS -EPEAS)
}

\author{
Luiz Marcelo de Carvalho ${ }^{1}$
}

\begin{abstract}
Resumo
Estimulado pelos debates que se desenrolaram na mesa redonda Demandas e Agendas de Pesquisa em Educação Ambiental, realizada durante o VIII EPEA, da qual participei, busco, neste artigo, sistematizar algumas análises e reflexões que levei para discussão naquela oportunidade, relacionadas com esse campo de pesquisa. Assim, procuro, inicialmente, explicitar algumas perspectivas metodológicas que escolho como uma alternativa para as possíveis e diversas possibilidades de respostas à questão proposta para a mesa redonda. Tal escolha é o caminho que encontro para vencer as dificuldades iniciais frente à complexidade da temática, certo de que as respostas dadas só poderão ser entendidas como tentativas, provisórias e temporárias, em um contexto particular. Procuro, sinteticamente, fazer menção a algumas estratégias de consolidação e de transformação do campo que a comunidade de pesquisadores em EA tem construído. A partir desse contexto, faço, finalmente, um esforço no sentido de apontar possíveis agendas e demandas que poderiam ser vistas como pertinentes para o campo. Para tal, exploro relatos dos trabalhos dos Grupos de Discussão de Pesquisa (GDPs), que vêm sendo publicados pela revista Pesquisa em Educação Ambiental, desde 2005, e a cada edição do EPEA. A aposta é a de que os resultados desse exercício, realizado pós VIII EPEA, sejam vistos como possíveis elos em uma cadeia de enunciados que concorrem em processos de produção de sentidos sobre o campo da pesquisa em EA no Brasil.
\end{abstract}

Palavras-chave: Pesquisa em Educação Ambiental. Encontros de Pesquisa em Educação Ambiental. Grupos de Discussão de Pesquisa. Agenda de Pesquisa em Educação Ambiental.

\section{DEMANDS AND AGENDAS OF ENVIRONMENTAL EDUCATION RESEARCH IN BRAZIL: MEANINGS BUILT FROM THE REPORTS OF RESEARCH GROUPS IN ENVIRONMENTAL EDUCATION (GDPS -EPEAS)}

\begin{abstract}
Encouraged by the debates that took place at the round table Research Demands and Agendas on Environmental Education, held during the VIII EPEA and in which I participated, in this article, I seek to systematize some analyses and reflections that I brought to discussion in relation to such field of research on that occasion. Thus, I initially try to make explicit some methodological perspectives that I choose as an alternative to the possible and diverse possibilities of answers to the question proposed for the round table. Such a choice is the way that I find to overcome initial difficulties in face of the complexity of the subject, being certain that the answers given can only be understood as tentative and temporary, in a particular context. From that point on, I try to mention some consolidation and transformation strategies of the field that the community of researchers in EE has built. Considering this context, I, finally, make an effort to point out possible agendas and demands that could be

\footnotetext{
${ }^{1}$ Luiz Marcelo de Carvalho, professor do programa de Pós-graduação em Educação, Instituto de Biociências, Universidade Estadual Paulista Júlio de Mesquita Filho (Rio Claro), São Paulo, Brasil.
} 
seen as pertinent to the field. To that end, I explore reports of the studies by the Research Discussion Groups (GDPs) that have been published by the journal Environmental Education Research since 2005 and in each issue of EPEA. The aim is that the results of this exercise, carried out after the VIII EPEA, will be seen as possible links in a chain of statements that compete in meaning making processes about the field of EE research in Brazil.

Keywords: Research in Environmental Education. Environmental Education Research Meetings. Research Discussion Groups. Environmental Education Research Agendas.

\section{DEMANDAS Y AGENDAS DE INVESTIGACIÓN EN EDUCACIÓN AMBIENTAL EN BRASIL: SIGNIFICADOS CONSTRUIDOS A PARTIR DE LOS INFORMES DE LOS GRUPOS DE DISCUSIÓN DE PESQUISA EN EDUCACIÓN AMBIENTAL (GDPS -EPEAS)}

\section{Resumen}

Estimulado por las discusiones que tuvieron lugar en la mesa redonda Demandas y Agendas de Investigación en Educación Ambiental, realizada durante el VIII EPEA, de la cual he participado, busco, en este artículo, sistematizar algunos análisis y reflexiones que introduje a discusión en aquel momento, en relación con este campo de investigación. Por lo tanto, trato de explicar, inicialmente, algunas perspectivas metodológicas para elegir como alternativa a las posibles y varias respuestas a la pregunta planteada por la mesa redonda. Esta elección es la manera que encuentro para superar las dificultades iniciales que se enfrenta delante de la complejidad del tema, seguro que las respuestas sólo pueden interpretarse como intentos, provisionales y temporales, en un contexto particular. A partir de ahí, trato de destacar algunas de las estrategias de consolidación y transformación del campo que la comunidad de investigación en EA ha construido. Por último, hago un esfuerzo para identificar posibles agendas y demandas que podrían considerarse como relevantes para el área. Para ello, exploro los informes de los trabajos de los Grupos de Discusión de Pesquisa (GDPs), publicados en la revista Pesquisa en Educación Ambiental, desde 2005, y a cada edición del EPEA. La apuesta es que los resultados de este ejercicio, llevado a cabo después del VIII EPEA, sean vistos como posibles eslabones de una cadena de enunciados que compiten en forma de procesos de producción de sentidos en el campo de la investigación en educación ambiental en Brasil.

Palabras-clave: Investigación en Educación Ambiental. Encuentros de Pesquisa en Educación Ambiental. Grupos de Discusión de Pesquisa. Agenda de Investigación en Educación Ambiental.

\section{Introdução}

Decorridos quinze anos da realização do I Encontro de Pesquisa em Educação Ambiental (EPEA), realizado em 2001, no Campus da Unesp, em Rio Claro, a oitava edição desse evento - coordenada por pesquisadores vinculados a diferentes grupos de pesquisa em EA do Estado do Rio de Janeiro, e sediada no Campus da Universidade Federal do Estado do Rio de Janeiro (Unirio) - propõe como mote para as discussões de uma das mesas redondas do evento o tema Demandas e Agendas de Pesquisa para o Campo da Educação Ambiental (EA).

Convidado pela comissão coordenadora do evento para participar dessa sessão, e alinhavar algumas ideias para iniciar as discussões da temática proposta, a sensação primeira 
foi de imobilidade diante do tema, devido à complexidade da tarefa que se apresentava, considerada, em um primeiro momento, como impossível de ser levada adiante. Apenas o exercício paciencioso de busca pela relativização da tarefa, pela aceitação dos limites pessoais que se impõem frente à dimensão da proposta, abriu-me caminhos possíveis para o trabalho. Caminhos, estes, que passam por tentativas, na maioria das vezes muito arriscadas, de simplificar o que se sabe complexo, de caracterizar como plural o que não pode ser pensado apenas no singular, mas é, muitas vezes, assim tratado. Assim, valendo-me do recurso do itálico para enfatizar que a busca se dará por possíveis agendas, o imobilismo só começa a ceder espaço para o trabalho minimamente produtivo, com a relativização do compromisso, que passa a ser entendido como um exercício que se apresenta aberto a perspectivas e possibilidades múltiplas.

Tais estratégias colocaram-me, assim, diante de um relativa tranquilidade interna e de possibilidades metodológicas concretas, permitindo-me sair do imobilismo e ir à busca de respostas, vistas, agora, apenas como tentativas temporárias, provisórias, contingentes, transitórias... O que se apresentava como impossível, foi assumindo concretude, na medida em que contextualizado e entendido como um esforço na proposição do que pode ser visto apenas como mais um elo de uma cadeia infinita de enunciados (BAKHTIN, 2009, 2010).

Sendo assim, como exercício de construção discursiva do campo da pesquisa em EA, procuro trazer alguns elementos como parte desse processo de construção de sentidos sobre a realidade, sobre a temática ambiental, sobre a perspectiva da EA e da pesquisa em EA. Mais que uma construção individual e descontextualizada, entendo estes apontamentos como resposta e continuidade ao que vem sendo posto por outros pesquisadores sobre o campo da pesquisa em EA, principalmente no Brasil, esperando que gerem outras respostas e se concretizem, de fato, como um elo nesse processo infinito de construção de enunciados e de sentidos.

Em um campo bastante sujeito à construção de consensos, muitos deles aparentes e, muitas vezes, sem respaldo empírico ou teórico, as análises de textos que se voltam para a reflexão sobre a pesquisa em EA são unânimes em apontar para sua complexidade. Se aceitamos a já mencionada proposição de Carvalho (2009), que entende a EA como uma esfera que se constitui na confluência de dois campos já por si revestidos da perspectiva da complexidade - quais sejam, o ambiental e o educacional - pouco temos a contrapor a essa compreensão.

Essa constatação consensual quanto à complexidade tanto do campo ambiental quanto da própria EA e, consequentemente da pesquisa em EA, implica, necessariamente, numa produção acadêmica reconhecida por Carvalho (2009, p. 128-129) como "ainda bastante aberta e com baixa definição", ou "com vários atravessamentos e um baixo perfil de definição".

Os questionamentos que têm sido levantados por alguns autores (CARVALHO, 1989, 2010; TOZONI-REIS， 2008; PAYNE， 2009; CARVALHO， 2009; CARVALHO; TOMAZELLO; OLIVEIRA, 2009; TREIN, 2012; LAYRARGUES; LIMA, 2014, entre outros) em relação aos sentidos que temos construído sobre EA e sobre a pesquisa em EA, são de fato relevantes. Em trabalhos anteriores a este (CARVALHO, 2016; CARVALHO; KAWASAKI, no prelo); CARVALHO et al., s/d ${ }^{2}$ ), nos quais procuro sistematizar alguns aspectos do debate sobre o campo da pesquisa em Educação Ambiental, tenho destacado certos vieses da relação entre o campo da EA e o da pesquisa em EA, que me parecem

\footnotetext{
${ }^{2}$ Texto elaborado para compor uma coletânea sobre Pesquisa em Educação Ambiental no Brasil e proposto para ser publicado no periódico Environmental Education Research. A proposta para a publicação desse número especial está em fase final de avaliação pelos editores do referido periódico).
} 
significativos e que considero fundamentais, uma vez que vistos como contextos que dão contornos às demandas e às possíveis agendas para o campo. Assim, retomo alguns dos aspectos já salientados nesses trabalhos, procurando problematizar, aqui, a prática da pesquisa em EA.

Referindo-se ao campo da EA, Payne (2009) chama a atenção para alterações de naturezas conceitual, ontológica, epistemológica e metodológica que vimos experimentando em relação à Educação Ambiental, desde os anos 1970. Dos objetivos postos na década de 1970, visando transmitir conhecimentos factuais sobre e, frequentemente, no ambiente, são observadas mudanças significativas, que passam a considerar perspectivas para uma educação política e socialmente crítica, inspiradas em adeptos das teorias críticas. Os movimentos da chamada "virada linguística", ou mesmo da considerada "virada corporal", os convites aos discursos globalizados, a força da lógica global da educação para a sustentabilidade, as ênfases nas perspectivas pós-críticas/pós-estruturalistas são algumas das tendências que influenciaram e influenciam uma diversidade de correntes que alimentam o campo ao final do século XX e início do século atual (PAYNE, 2009, p. 56-57). Stevenson et al., (2013) e Gough (2013a) chamam a atenção para esta complexificação de um campo novo e marcado por intensos processos de transformação, que reage e resiste àqueles que ainda insistem na delimitação de pressupostos, princípios e interpretações em uma seara que envolve perspectivas disciplinares e interdisciplinares múltiplas. Segundo Payne (2009), a despeito de essa diversidade ser celebrada por muitos como uma caraterística saudável para o campo e para as práticas democráticas, por incluir diferentes perspectivas teórico-metodológicas, cresce a preocupação quanto ao significado histórico e valor estratégico do campo e quanto à falta de coerência, de identidade e de propósitos coletivos.

Parece-me que esses esforços em procurar compreender os processos de constituição do que somos e de onde estamos nos permitem vislumbrar possibilidades de nos tornarmos diferentes, de produzirmos algo também diferente, e de problematizarmos os slogans e as crenças já enraizados em nossas histórias, ou os pressupostos que se tornam consensuais (GOUGH, 2013b). São exercícios que configuram a possibilidade de distanciamentos necessários, de novas interrogações; de pensar o não pensado (LEFF, 2002); de exercer a criticidade e a criatividade na construção de significados sobre o mundo, sobre a temática ambiental e sobre o processo educativo.

Como muito bem salienta Carvalho (2009, p. 128-129), são exercícios que buscam construir "nossos autorretratos". Essa busca constante, no sentido de traçar o nosso perfil, nossa identidade, de mapear correntes, abordagens, tendências da EA, é um sinal claro da condição heterônoma ${ }^{3}$ do campo, "com vários atravessamentos e um baixo perfil de definição", ou seja, uma área que busca sua afirmação.

É esse o contexto, e são essas indagações iniciais, a partir dos quais procuro me voltar, considerando todas as relativizações já anunciadas, para o tema proposto para nossas reflexões: demandas e (possíveis) agendas da pesquisa em EA. Procuro, inicialmente e de forma muito sucinta, mencionar algumas estratégias de consolidação desse campo de pesquisa, que vem se concretizando a partir dos esforços de uma dinâmica comunidade nacional e internacional de pesquisadores debruçados sobre essa área do conhecimento.

Em um segundo momento, tendo como referência os textos que fazem os relatos dos trabalhos realizados pelos Grupos de Discussão de Pesquisas, que vêm se reunindo nos Encontros de Pesquisa em Educação Ambiental, desde 2005, procuro, a partir de uma leitura inicial dos mesmos e sem a pretensão de esgotá-los, destacar alguns aspectos postos pelos

\footnotetext{
${ }^{3}$ Heteronomia está sendo, aqui, utilizado na concepção bourdieuniana do termo, explorado de forma mais detalhada em Carvalho (2016).
} 
GDPs que podem ser vistos como demandas e agendas para a pesquisa nesse campo de conhecimento.

\section{Os Movimentos de um Campo de Pesquisa - estratégias de consolidação do campo de pesquisa em EA}

Quando de minha participação na mesa redonda realizada no VIII EPEA, empenheime em sistematizar e apresentar alguns exemplos concretos que evidenciam os esforços da comunidade de pesquisadores em EA, no Brasil e no mundo, no sentido de construção de estratégias que não apenas garantam a divulgação/circulação do conhecimento gerado, mas que também estimulem e fomentem a cadeia infinita de produção de sentidos (BAKHTIN, 2009) sobre a EA e sobre a pesquisa nesse campo. Procurei, naquela oportunidade, salientar os vários caminhos que a comunidade de pesquisadores em EA tem explorado, e que vem se apresentando como estratégias potentes de consolidação/subversão desse campo de conhecimento.

Estimulado por esse exercício inicial, procurei dar continuidade à sistematização dos movimentos empreendidos pela comunidade de pesquisadores desse campo de pesquisa. Nesse caminho, procurei me aproximar de autores que vêm se apropriando da noção bourdieuniana de campo científico (BOURDIEU, 1983, 2004), com a intenção de refletir sobre os movimentos de consolidação, reconhecimento, conservação e subversão que a comunidade de pesquisadores tem trilhado e, dessa forma, compreender, pelo menos em parte, a história desse campo de conhecimento.

Os resultados desse trabalho estão, hoje, sistematizados em um texto elaborado como requisito para a minha participação em um concurso de livre-docência, intitulado Pesquisa em Educação Ambiental no Brasil: um campo em construção? (CARVALHO, 2016). Considerando que os limites deste artigo não me permitem sistematizar, de forma mais detalhada, os resultados desse trabalho e nem mesmo retomar e apresentar os resultados parciais apresentados naquela mesa redonda, a alternativa que me pareceu mais plausível para este texto foi a de, apenas, indicar cada uma das estratégias às quais fiz referência na mesa redonda e que foram analisadas mais detalhadamente no mencionado texto. Deixo para o leitor a indicação e o linque do texto integral, no qual apresento, de forma minuciosa, resultados concretos desses diferentes movimentos da comunidade de pesquisadores em EA, referentes às diferentes estratégias de consolidação desse campo de pesquisa ${ }^{4}$.

Dentre as várias e possíveis estratégias que uma comunidade de pesquisadores escolhe como caminhos de consolidação de um campo de conhecimento, a estruturação de mecanismos que garantam a circulação e socialização dos conhecimentos produzidos pode ser vista como uma das mais importantes, alcançando, mesmo, a condição sinae qua non para a sobrevivência de um determinado campo de conhecimento. Além das diversas publicações científicas na modalidade de periódicos, procurei destacar nessas duas ocasiões (mesa redonda e texto de livre-docência) as seguintes estratégias, que, me parece, têm sido exploradas pela comunidade de pesquisadores: a) - os trabalhos na linha do estado da arte ou estado do conhecimento; b) - as aproximações e vinculações dos grupos de pesquisa em EA

\footnotetext{
${ }^{4}$ Texto elaborado como requisito para obtenção do título de Livre-Docência em Educação Ambiental, junto ao Instituo de Biociências, Departamento de Educação, Unesp, Rio Claro. Disponível em www.Imcarvalho.blogspot.com
} 
com associações nacionais e internacionais de pesquisa na área da Educação; c) - a organização e estruturação de um número muito significativo de grupos de pesquisa espalhados por todo o território nacional e, d) - os eventos nacionais e internacionais que vêm ganhando destaque e projeção em nível mundial.

\section{Demandas e agendas de pesquisa em EA - O que nos indicam as discussões nos GDPs - EPEAs?}

Assim que tomei contato com o tema proposto para a mesa redonda do VIII EPEA, para a qual estava prevista minha participação, e passadas as primeiras sensações de impotência e de imobilismo frente à complexidade da temática proposta, a busca por elementos que pudessem me orientar na sistematização de algumas ideias para discussão, levaram-me, sem muito demora, a um material que se apresentava como de grande significado para exercícios como os propostos pela equipe organizadora do evento. Estou me referindo aos textos que relatam os resultados dos Grupos de Discussão de Pesquisa (GDPs), que vêm sendo publicados bienalmente pela revista Pesquisa em Educação Ambiental nos números dedicados a divulgar os textos das Conferências, Mesas redondas e GDPs de cada uma das edições do EPEA.

Os GDPs foram propostos a partir do III EPEA, em 2005, como uma nova modalidade para a discussão, em grupos, das pesquisas apresentadas no evento. Segundo os organizadores, e indicado na página do evento, a ideia foi oferecer aos participantes do encontro mais um espaço para discussão das pesquisas, apresentadas no evento, mas desta vez, procurando articular conjuntos de trabalhos com determinados eixos temáticos propostos pela organização do evento. Cada um desses grupos reúne-se em duas sessões de duas horas de duração, coordenadas por pesquisadores convidados, com experiência no desenvolvimento de pesquisas relacionadas com a temática proposta. Os coordenadores dos diferentes GDPs, a partir de uma análise prévia dos trabalhos apresentados no evento e vinculados pelos autores ao respectivo GDP, preparam um texto com questões que deverão motivar as discussões nos grupos. Ao final do evento, os coordenadores dos diferentes GDPs participam de uma mesa redonda, quando fazem o relato das discussões ocorridas no grupo. Os diferentes textos são, depois, publicados, como já mencionado, pelo periódico Pesquisa em Educação Ambiental, no ano subsequente ao da realização do evento.

O Quadro 1 apresenta os temas desenvolvidos nos GDPs desde 2005, a cada dois anos, nas edições subsequentes dos EPEAs. Como se pode observar por esse quadro, alguns dos temas propostos como mote para as discussões, por serem muito específicos ou por terem sido agrupados a temáticas mais abrangentes de outros GDPs, não tiveram continuidade em todas as edições dos EPEAs.. Outras temáticas vêm se mantendo durante todo esse período, como é o caso do GDP Pesquisa em EA e Questões Epistemológicas, Pesquisa em EA e Contexto Escolar, Pesquisa em EA e Formação de Educadores / Professores, Pesquisa em EA e Movimentos Sociais (a esse último, nas duas edições mais recentes do EPEA, foi associado o termo Justiça Ambiental). Outras temáticas propostas mais recentemente vêm se mantendo e indicam, pelas discussões que vêm sendo realizadas no interior dos GDPs, interesse dos pesquisadores em relação à sua continuidade, como é o caso do tema Pesquisa em EA e Questões Metodológicas, Pesquisa em EA e Contexto Não Escolar, Pesquisa em EA e Políticas Públicas e, mais recentemente, Pesquisa em EA e Culturas.

Os relatórios de cada um dos GDPs procuram enfatizar as questões que a cada evento são privilegiadas e procuram, ainda, destacar as tendências que vêm se apresentando como mais significativas. Sendo assim, esse conjunto de textos, de fato, pode oferecer informações de grande interesse para aqueles que procuram mapear aspectos mais específicos de um 
determinado campo do conhecimento, apontando para aqueles que mereçam maior atenção dos pesquisadores, e, como proposto por Gough (2004), e Reid e Scott (2013), de alguma forma oferecer elementos que nos ajudem a identificar pontos em branco, pontos cegos ou pontos frágeis de nossas pesquisas. Em última análise, esses textos se apresentam como um material privilegiado na tarefa e na busca por demandas e agendas de pesquisa em EA.

O contato com o conjunto dos relatos dos trabalhos desenvolvidos pelos GDPs, ao longo desses dez anos, e publicados pela revista Pesquisa em Educação Ambiental ${ }^{5}$, apenas reforçam a expectativa quanto ao potencial desses textos em apontar para aspectos significativos da pesquisa em EA no Brasil. O Quadro 1 apresenta as temáticas discutidas nos grupos na década entre 2005-2015.

\begin{tabular}{|l|l|l|l|l|l|l|}
\hline GRUPOS DE DISCUSSÃO DE PESQUISA/ ANO & $\mathbf{2 0 0 5}$ & $\mathbf{2 0 0 7}$ & $\mathbf{2 0 0 9}$ & $\mathbf{2 0 1 1}$ & $\mathbf{2 0 1 3}$ & $\mathbf{2 0 1 5}$ \\
\hline Pesquisa em EA e Questões Epistemológicas & $\mathrm{X}$ & $\mathrm{X}$ & $\mathrm{X}$ & $\mathrm{X}$ & $\mathrm{X}$ & $\mathrm{X}$ \\
\hline Pesquisa em EA e Questões Metodológicas & & & & $\mathrm{X}$ & $\mathrm{X}$ & $\mathrm{X}$ \\
\hline Pesquisa em EA e Contexto Escolar & $\mathrm{X}$ & $\mathrm{X}$ & $\mathrm{X}$ & $\mathrm{X}$ & $\mathrm{X}$ & $\mathrm{X}$ \\
\hline $\begin{array}{l}\text { Pesquisa em EA e Formação de Educadores / } \\
\text { Professores }\end{array}$ & & $\mathrm{X}$ & $\mathrm{X}$ & $\mathrm{X}$ & $\mathrm{X}$ & $\mathrm{X}$ \\
\hline Pesquisa em EA e Contexto Não Escolar & & & & $\mathrm{X}$ & $\mathrm{X}$ & $\mathrm{X}$ \\
\hline Pesquisa em EA e Políticas Públicas & & $\mathrm{X}$ & & $\mathrm{X}$ & $\mathrm{X}$ & \\
\hline Pesquisa em EA e Movimentos Sociais & & & $\mathrm{X}$ & & & $\mathrm{X}$ \\
\hline $\begin{array}{l}\text { Pesquisa em EA, Movimentos Sociais e Justiça } \\
\text { Ambiental }\end{array}$ & & & & & $\mathrm{X}$ & $\mathrm{X}$ \\
\hline Pesquisa em EA e Culturas & & $\mathrm{X}$ & & & & \\
\hline Pesquisa em EA e Pesquisa Ação & $\mathrm{X}$ & & & & & \\
\hline Pesquisa em EA e Temas Controversos & $\mathrm{X}$ & & & & & \\
\hline Pesquisa em EA e Sustentabilidade & $\mathrm{X}$ & & & & & \\
\hline Pesquisa em EA e Intervenções Sociais & & $\mathrm{X}$ & & & & \\
\hline Pesquisa em EA e Percepção Ambiental
\end{tabular}

Quadro 1 - GDPs propostos e desenvolvidos em cada uma das edições dos Encontros de Pesquisa em Educação Ambiental, desde 2005

Fonte: Pesquisa em Educação Ambiental. Organizado pelo autor

Assinaladas as temáticas, procuro, a seguir, pontuar alguns dentre vários aspectos que podem ser explorados a partir da leitura e análise desses textos. A síntese proposta não tem a pretensão de esgotar as potencialidades que se apresentam de construção de sentidos sobre demandas e agendas de pesquisa para o campo da EA, a partir das análises desses textos. Mais uma vez, a natureza de tais textos nos impõe limites em termos de extensão do artigo e, diante deles, o caminho plausível é o de fazer escolhas.

$\mathrm{Na}$ sequência deste texto, procuro apontar para alguns, dentre outros múltiplos aspectos que o convite proposto, a leitura desses textos e as minhas experiências no campo da pesquisa em EA, suscitam e indicam como demandas e agendas que considero plausíveis para o campo da pesquisa em EA.

\footnotetext{
${ }^{5}$ Especificamente: vol. 2, n. 1, 2007; vol. 3, n. 1, 2008; vol. 4, n. 2, 2009; vol. 7, n. 2, 2012; vol. 9, n. 1, 2014 e vol. 11, n. 2, 2016)
} 


\subsection{Pesquisa em EA e os referenciais teóricos e metodológicos}

Em meio a uma diversidade de questões presentes nos relatos de pesquisa dos GDPs, considerações relativas à necessária explicitação dos referenciais teórico-metodológicos que orientam os processos de produção de conhecimento têm sido recorrentes, principalmente quando se trata dos textos dos GDPs Pesquisa em EA e Questões Epistemológicas e Pesquisa em EA e Questões Metodológicas. É interessante observar, no entanto, que a leitura do conjunto dos relatos nos permite considerar que essa se apresenta como uma demanda dos pesquisadores reunidos nos mais diversos GDPs, e que vem sendo entendida como central e de grande relevância para o campo da pesquisa em EA, ao longo desses anos.

Assim, a necessidade de se explicitar, com clareza, em nossos relatos de pesquisa os marcos teóricos e metodológicos que fundamentam e orientam o desenvolvimento dos trabalhos, se faz presente em diversos relatos dos GDPs e marcam os debates dos grupos de pesquisadores que têm participado dos EPEAs. Essa parece ser a condição para uma maior consistência, confiabilidade e reconhecimento quanto à validade e valor social dos resultados de nossos trabalhos (TREIN, 2012).

O reconhecimento de que o objeto de estudo dos pesquisadores em EA tem um caráter fundamentalmente interdisciplinar, permitindo e exigindo uma grande aproximação com campos do conhecimento dos mais diversos - quer sejam da área das ciências da natureza, das tecnologias ou das ciências humanas e sociais (FLORIANI, 2009) _ não nos exime da busca de coerência interna em relação às perspectivas ontológicas, epistemológicas e metodológicas que orientam nossas práticas sociais de produção de conhecimento.

O reconhecimento quanto à necessária coerência e consistência teórico-metodológica nas pesquisas do campo da EA, no entanto, não pode ser visto, conforme alertam Trein e Cavalari (2014), como adesão a dogmatismos, aos argumentos de autoridade sem um "maior aprofundamento a respeito da consistência, da pertinência e também das implicações epistêmico-políticas da opção assumida (GOERGEN, 2010, p.15).

Assim, parece estar marcado, em nossos debates, que não se trata da defesa de dogmatismos ou de exigências de aproximações com modelos fiéis ao pensamento hegemônico. Este, segundo, Trein (2012, p.82), "tende a se apresentar como universalmente válido e naturaliza conceitos e categorias de análise, induz a falsos consensos, obliterando divergências e simulando harmonias". Tal caminho, segundo a autora, nos impediria de reconhecer o potencial de dominação que as ciências podem ter, e suas consequências sociais pouco desejáveis, tanto para os humanos como para os outros elementos da natureza.

Considerando, conforme propõem Trein e Cavalari (2014), que tais fragilidades não se constituem privilégios do campo da pesquisa em EA, o caminho que se vislumbra como plausível não passa por elegermos uma epistemologia própria - considerando que o próprio campo da educação "é um espaço de confluência e mestiçagem de conhecimentos, indo buscar nessas interseções um diálogo com o seu campo em construção" (FORIANI, 2009, p. 200). Sendo assim, segundo esse autor, cabe-nos a tarefa "de desenvolver novas culturas epistemológicas, sem a pretensão de criar um novo paradigma hegemônico".

Mais do que uma única orientação teórico-metodológica, o que importa para TozoniReis e Souza (2014) é que as questões epistemológicas e metodológicas que orientam a pesquisa tenham coerência e consistência internas. Nessa direção, a crítica às perspectivas epistemológicas e visões de mundo eurocêntricas marcam os debates em algumas das sessões dos GDPs (TREIN, 2012; TREIN; CAVALARI, 2014). A proposta de que as pesquisas em EA possam se alimentar dos teóricos que têm proposto e investido na construção de uma 
"epistemologia do Sul" (CAMARGO; TONSO, 2013. p. 1) ou de uma "filosofia da América Latina" (COSTA, 2016) sugere o enfrentamento em relação às perspectivas colonialistas, com sérias críticas às epistemologias hegemônicas que consideram o desenvolvimento científico como panaceia para todos os males do século, incluindo as diversas modalidades de degradação ambiental.

O embate teórico tem sido entendido como necessário, nas palavras de Trein (2012), caso queiramos alimentar expectativas sobre a possibilidade de se propor alternativas que possam ser, de fato, transformadoras, visto que é esse enfrentamento que nos possibilita identificar, analisar e avaliar os problemas, no verdadeiro sentido dessa palavra, que afetam as sociedades contemporâneas. Assim, essa autora entende que as questões epistemológicas devem ser entendidas à luz da matriz ontológica que as fundamenta:

De que sociedade humana estamos falando? Que relações temos estabelecido com o meio natural? Que cultura daí decorre? Que processos educativos se gestam no incessante intercâmbio entre os seres humanos e a natureza e entre os seres humanos, fertilizando as transformações do mundo e a autotransformação dos sujeitos? (TREIN, 2012, P. 86)

O olhar para esse conjunto de textos nos permite, por fim, reconhecer que essa busca pela explicitação e aprofundamento das questões teóricas que estão sempre presentes em nossas práticas sociais de produção de conhecimento, aponta, como demanda e como agenda, de um lado, para a necessária articulação, coerente e consistente, entre ontologia, epistemologia e metodologia, perspectiva esta que tem sido uma tônica não só entre os relatos dos GDPs, mas entre outros pesquisadores que têm enfatizado a propriedade de tais relações (PAYNE, 2009).

Por outro lado, essa exigência nos coloca em sintonia com o necessário exercício de explicitar e aprofundar as nossas compreensões quanto aos conceitos-chave que circundam os nossos problemas de investigação. São várias as chamadas dos pesquisadores, no sentido de apontar para o necessário aprofundamento em relação ao conceito e sentidos de educação, para o necessário rigor conceitual em torno do termo ambiental, para a necessidade de explicitação quanto às relações que estabelecemos entre a prática educativa e a temática ambiental, quanto ao conceito de sustentabilidade que, muitas vezes, se apresenta como central em nossas propostas e práticas pedagógicas.

Por fim, o que fica claramente posto pelas reflexões e entendimentos que temos construídos a partir de nossas discussões nos GDPs, é que a emergência e a urgência no enfrentamento em relação aos modelos que determinam os atuais padrões de relação sociedade-outros elementos da natureza não podem ser justificativas para simplificações ou aligeiramentos em relação ao rigor e ao aprofundamento teórico. A relação intrínseca entre teoria e prática é que poderá nos informar e apontar caminhos efetivos de transformação social na busca de construção, por meio de práticas democráticas, de um mundo no qual, em nossos horizontes coletivos, a justiça social e ambiental sejam utopias a serem concretizadas.

\subsection{Pesquisa em EA e as Perspectivas Críticas para a Interpretação da realidade}

Diretamente associado às questões relativas aos referenciais teórico-metodológicos das pesquisas no campo da EA, os textos dos GDPs reconhecem a adesão, por parte de muitos dos investigadores do campo, às acepções que associam EA com interpretações da realidade entendidas como críticas.

De fato, os autores desses textos se somam a outros tantos que discutem a pesquisa em EA (ver CARVALHO, 2016, por exemplo) e também identificam nos relatos de algumas de 
nossas pesquisas, menção a perspectivas críticas que apostam em processos de emancipação e de transformação social. No entanto, esse possível consenso carece de análises mais criteriosas, antes que se tornem mais um dentre outros tantos falsos consensos construídos a partir de nossas práticas discursivas.

Primeiro, penso ser necessário uma análise mais criteriosa em relação aos posicionamentos político-ideológicos expressos nos relatos de pesquisa do campo. Por exemplo, quando tomamos como referência, para análises de conjunto de artigos ou teses e dissertações, as macrotendências propostas por Layrargues e Lima (2014), a associação de algumas passagens desses textos com as macrotendências conservadora e pragmática é inevitável. O importante a considerar, em nossa interpretação, é que essas são também perspectivas políticas presentes em nossos trabalhos e tidas como referenciais plausíveis por muito pesquisadores.

Nesse sentido, julgo necessário o cuidado para não alimentarmos a falsa ideia de que as perspectivas crítica e emancipatória estão se fazendo presentes em nossos textos sem conflitos, controvérsias ou lutas político-ideológicas, na busca por conquista de espaços hegemônicos no campo da pesquisa em educação ambiental. Embora a perspectiva crítica tenha conquistado alguns espaços, principalmente no campo da produção do conhecimento da área, conforme apontam Layrargues e Lima (2014, p. 35) "essas forças são constantemente erodidas pelo pragmatismo dominante que tende a converter e a deslocar as intenções educativas ao sentido pragmático do mercado". Assim, se aceitarmos a provocação dos autores no sentido de que as pesquisas podem nos ajudar a "diagnosticar as hegemonias discursivas na Educação Ambiental", a análise mais aprofundada desse conjunto de trabalhos que deixa entrever indicadores das perspectivas "conservacionistas e pragmáticas" pode se constituir em exercícios relevantes, no sentido de compreendermos os movimentos de construção desse campo de produção de conhecimentos.

Tais considerações, no entanto, não invalidam os esforços no sentido de compreendermos essa presença marcante das perspectivas críticas em boa parte de nossos textos de pesquisa. Para muitos, a filiação explícita a tais perspectivas constitui-se em exercício obrigatório e ponto de partida para as suas investigações. O que os textos dos GDPs têm enfatizado, acompanhando, também, outros tantos autores do campo, é a preocupação quanto aos sentidos e significados que temos construído associados à chamada EA crítica.

Segundo Cavalari e Trein (2016) os trabalhos analisados pelo GDP Pesquisa em EA e Questões Epistemológicas filiam-se, de um modo geral, às perspectivas reconhecidas como críticas. No entanto, a concepção de crítico nem sempre é suficientemente explicitada quanto à sua vertente epistemológica, e nem é explicitado como essa se distingue de outras concepções críticas. Afinal, segundo as autoras, faz-se necessário "esmiuçarmos" o que estamos entendendo "por EA crítica, teoria crítica, pensamento crítico, práticas educativas críticas e os contextos em que esses conceitos são mobilizados" (CAVALARI; TREIN 2016, p. 84).

Assim, uma vez que nem sempre estão claros os compromissos teórico-metodológicos que a opção pelas perspectivas críticas da EA implica (LIMA; CARVALHO, 2014), o que se observa é que subjacentes a essas perspectivas, "é possível identificar diferentes concepções de mundo e diferentes propostas de organização da sociedade" (TREIN, 2012, p. 82). Para essa autora, "as teorias críticas, entendidas como as que se contrapõem ao atual modo de produção social de vida, possuem diferenças e potencial heurístico entre si distintos e isso precisa ser mais profundamente estudado". Então, enfrentar o "embate teórico-metodológico" em relação às nossas interpretações da realidade configura parte das lutas contra-hegemônicas (TREIN, 2012, p.86). 
É nessa direção que Lima e Carvalho (2014) expressam suas preocupações com as pesquisas que no contexto escolar explicitam sua adesão às perspectivas críticas, mas que

[...] ao filtrar conflitos e embates acadêmicos e socioambientais e selecionar, sob o manto da sustentabilidade, consensos em torno dos quais não há desacordo, favorece discursos e práticas que não contribuem para a superação das graves realidades que se propõe a enfrentar (LIMA E CARVALHO, 2014, p. 154).

Sendo assim, parece admissível o entendimento de Cavalari e Trein (2016, p.96), de que temos que procurar "ir além da declaração de fé do pertencimento ao campo da teoria crítica", e nos empenharmos tanto em explicitar os pressupostos teóricos adotados como em nos apropriarmos, de forma mais rigorosa, das diferentes correntes epistemológicas. Enfim, tanto para essas autoras como para outros pesquisadores vinculados aos diferentes GDPs, a questão “a educação ambiental crítica é crítica de quê?”, formulada por Trein (2012, inserir p. na citação direta) continua a nos desafiar e a exigir respostas da comunidade de pesquisadores.

\subsection{Pesquisa em EA e Processos de Transformação Social}

O contato com os textos dos GDPs, motivado pela busca em sistematizar alguns aspectos que poderiam ser vistos como demandas e agendas para o campo da pesquisa em $E A$ nos coloca em sintonia como outra proposição que tem sido posta pelos pesquisadores do campo e que, entendemos, ganha centralidade nos debates: as possíveis relações entre a pesquisa em EA e os processos de transformação social. Entendida como, também, decorrente das questões relativas à consistência e coerência em relação aos referenciais teóricos e metodológicos da pesquisa no campo da EA, em especial aquelas relacionadas às perspectivas críticas, tal proposição sugere algumas nuanças para o debate, que, em meu entendimento, merecem nossa atenção.

No contexto brasileiro, como já explorado por Carvalho (2016), o próprio campo da pesquisa em educação se viu às voltas, ao final dos anos de 1970 e início de 1980, com a necessidade de dar uma resposta ao contexto político nacional, em um clima altamente repressivo e de supressão dos direitos individuais e de expressão coletiva. Naquele momento, houve a aproximação com os referenciais da teoria crítica e a possível associação entre as ações de pesquisa e ações de transformação social foi colocada na ordem do dia do campo da pesquisa em educação (GATTI, 2001, 2004).

É interessante observar que, muitas das escolhas quanto aos procedimentos metodológicos a serem adotados pelos investigadores, têm como justificativa o compromisso político e a intenção explícita de associação entre a pesquisa que se pretende desenvolver e os processos de transformação de uma determinada realidade. Assim, as metodologias da pesquisa-ação e da teoria do conflito (GATTI, 2001) ganham espaços significativos, tanto no Brasil como em outros países, enfatizando o significado que as perspectivas críticas, as abordagens e os tratamentos multidimensionais poderiam assumir na tentativa de compreensão, de forma mais ampla, dos problemas educacionais.

Gatti (2004), no entanto, alerta para o fato de que a relação entre pesquisa - ação e mudanças tem sido encarada e tratada de forma muito simplista pelo campo da pesquisa em educação, de maneira geral. Segundo a autora, embora não possamos menosprezar a importância e o caráter político de nossas investigações, bem como a necessária relação entre processos de produção de conhecimento e transformação social, tal perspectiva deve ser trabalhada, de um lado, evitando-se interpretações ingênuas e apressadas. 
Por outro lado, e para além dessa visão pragmática e imediatista, tal contexto também nos ajuda a compreender a relação, posta e enfatizada em muitos trabalhos, entre as próprias ações de pesquisa e o compromisso político dos pesquisadores, muitas vezes associado a processos de transformação social.

Apesar desses riscos, tal compromisso tem sido enfaticamente proposto e considerado como princípio fundamental, e tomado como orientação de grande significado para vários pesquisadores em EA no Brasil (LOUREIRO, 2004, 2008; HIGUCHI; MOREIRA JR.; 2009; HIGUCHI; ZATONI; BUENO, 2012; HIGUCHI; MAROTI, 2014). Esse contexto pode oferecer elementos que nos ajudam a compreender a perspectiva, até certo ponto pragmática, que se percebe em muitas das investigações desenvolvidas no país, no campo da pesquisa em EA. A tendência a certo imediatismo, e a busca de soluções urgentes para os problemas relacionados com impactos antrópicos provocados na natureza e no ambiente como um todo, já foram assinaladas por Cavalari, Santana e Carvalho (2006), Freitas e Oliveira (2006) e Pato, Sá e Catalão (2009) ao analisarem um conjunto de relatos de pesquisa do país.

No contexto de uma educação crítica, que considere os processos de emancipação e transformação social e que busque a construção da cidadania socioambiental, as metodologias participativas passam a ser vistas como elementos fundamentais a serem referenciados no campo da pesquisa em EA. Guimarães, Queiroz e Plácido (2014), por exemplo, ao sistematizarem os debates no campo da pesquisa em formação de professores, ressaltam a relevância de pesquisas que aprofundem essas referências, e enfatizam a pertinência da pesquisa-ação, pesquisa participante, pesquisa-formação como metodologias de pesquisa afins a esses propósitos.

Tal debate também ganha densidade nos relatos do GDP Pesquisa em EA e Contexto Escolar, quando, principalmente, Silva e Gomes (2008) pontuam que muitos dos relatos de pesquisa apresentados no IV EPEA fizeram uso de metodologias que partem do princípio da relação entre pesquisa e intervenção, explorando, assim, pesquisas participativas. Esse GDP, naquela oportunidade, deixou registrada a sua preocupação e os cuidados que entende serem necessários quando se considera tais abordagens metodológicas em processos de produção de conhecimento. Sem desconsiderar o potencial desses procedimentos metodológicos para a pesquisa no contexto escolar, no texto desse GDP chama-se a atenção para a necessidade de se cuidar para que as ações de pesquisa não se restrinjam, apenas, às ações de intervenção, associando aos dados empíricos o processo reflexivo e interpretação à luz das teorias que possam informar os processos de produção de conhecimento, levando-se em consideração que "o tempo da pesquisa é diferente do tempo da ação" (SILVA E GOMES, 2008, p. 253)

Para Higuchi, Zattoni e Bueno (2012) a premissa básica que orienta muitos dos projetos e as práticas da EA, qual seja, o empoderamento dos atores sociais envolvidos no processo, em contraposição a práticas sociais diversas, que inviabilizam os processos de transformação social e de promoção da justiça social, poderia, também, ser tomada como orientadora das pesquisas nesse campo. Afinal, que tipos de abordagens metodológicas seriam pertinentes e coerentes com tal perspectiva? Segundo Higuchi e Moreira Júnior (2009, p. 171) diante de realidades diversas e complexas, os pesquisadores vislumbram possibilidades de aproximação entre os pressupostos que vêm orientando as práticas de educação ambiental e as práticas de pesquisa, apontando para a necessidade de "deslocamentos metodológicos", inovação, engajamento e promoção de ações participativas. Tais anseios, por sua vez, indicam a necessidade de uma postura crítica em relação aos referenciais teóricos e metodológicos de pesquisa que nos permitam, para além da identificação e exploração dos problemas percebidos, a construção de ações cidadãs que promovam a construção de sociedades democráticas. 
Sendo assim, cabe-nos a busca, como pesquisadores, por compreender os limites, mas, também, os significados e sentidos que temos construído sobre tais perspectivas, que, de fato, abrem possibilidades para uma pesquisa mais engajada.

\subsection{Pesquisa em EA, contextos de produção e relação com o sistema de Pós-Graduação}

A reflexão sobre demandas e agendas para a pesquisa em EA e a tentativa de sistematizar essas demandas e agendas levaram-me a constatar, assim como diversos pesquisadores em debates nos GDPs, que não é oportuno desconsiderar as condições concretas e objetivas que se nos apresentam para as nossas práticas de produção de conhecimentos no campo da EA. Alguns dos relatos dos GDPs não se furtam em registrar os debates que caminharam nessa direção (TREIN; CAVALARI, 2014). Para essas autoras, a expectativa é que esses espaços de produção de conhecimento nos incentivem a tencionar nossas posições, explicitá-las, fundamentá-las e discuti-las em maior profundidade. Apontam, ainda, que essas seriam as condições necessárias para que, de fato, nossas pesquisas se tornassem "forças materiais de mudança, contornando o produtivismo, o individualismo e a postura competitiva". Esse não se parece em nada com o modelo de universidade que hoje se instaura em nossa realidade social, universidade "que pragmaticamente cobra resultados imediatos, que separa a pesquisa da docência, que direciona pautas de investigação à inovação com potencial mercadológico" (TREIN; CAVALARI, 2014, p. 130).

Que caminhos esses espaços poderiam, assim, nos oferecer para a prática de produção de um "conhecimento criativo e comprometido com as mudanças sociais e ambientais necessárias a um mundo menos desigual"? É nessa mesma direção que, no relato dos trabalhos do GDP Pesquisa em EA e Questões Metodológicas, que se reuniu em 2011 (VI EPEA), faz-se referência a um "certo conformismo pragmático" (TREIN; CAVALARI, 2014, p. 130) que

[...] domina o espaço acadêmico ao desconsiderar a realidade material em que a própria ciência é produzida e as imposições externas que vão paulatinamente sendo internalizadas por submissão aos processos de avaliação pelos pares, muitas vezes com regras próprias e consolidadas por outros campos do saber (TREIN, 2012, p.130).

Ao debruçar-me sobre o desenvolvimento da pesquisa no campo da EA e sua relação com os contextos de produção de conhecimento em nosso país, os dados passíveis de registro revelam questões das mais instigantes para o campo. Dois aspectos se destacam, a meu ver, a partir dos estudos até agora realizados: de um lado, a constatação de que a pós-graduação se constitui em um lócus privilegiado para o desenvolvimento das pesquisas em EA (CARVALHO; TOMAZELLO; OLIVEIRA, 2009) e, de outro lado, a grande diversidade das áreas de conhecimento às quais os diferentes programas estão vinculados. Os mais diversos pesquisadores que se voltam para esse contexto são enfáticos em assinalar, corroborando a constatação de Fracalanza (2004; 2005): a produção acadêmica e científica sobre a temática ambiental é realizada dentro dos mais diversos programas de pós-graduação, vinculados a distintas áreas de conhecimento.

No caso mais específico dos contextos de produção da EA, tal associação com o sistema de pós-graduação sugere, para Carvalho, Tomazello e Oliveira $(2009$, p. 21) que "a tentativa de compreender os caminhos de produção da pesquisa em educação ambiental no Brasil passa pela necessária compreensão dos caminhos da pós-graduação brasileira". Ao articular as questões epistemológicas com o contexto em que as pesquisas são produzidas, Trein (2012, p.80), ao sistematizar as discussões ocorridas no GDP Pesquisa em EA e 
questões metodológicas, registra o entendimento do grupo de que não se pode "desconsiderar que a pesquisa em EA influencia e é influenciada pelo perfil dos programas de pós-graduação e também pela política nacional de pós-graduação vigente no país, incluindo-se aí ainda um aspecto importante, que é a avaliação à qual os programas estão submetidos”. Nessa mesma direção, os trabalhos de Lorenzetti (2008), Molon (2008) e Reigota (2012) acentuam questões importantes sobre o significado e o lugar do meio acadêmico, em especial dos programas de pós-graduação, como espaços de formação do pesquisador e do educador em EA.

A ênfase na produção e na chamada "cultura da performatividade" (Moreira, 2009, p. 23), o paper como um fim em si mesmo, um certo descaso ou aversão à produção teórica, à atitude intelectual, têm sido apontados como tendências que têm limitado as pesquisas e, muitas vezes, comprometido o rigor e a consistência teórica, fundamentais nos processos de produção do conhecimento. Possivelmente, como resultado desse processo, o que se observa é uma tendência uniformizadora dos programas, condicionada a critérios definidos pelas áreas de conhecimento às quais estão associados, tendo como objetivo a avaliação do sistema como um todo e dos programas em particular (MOREIRA, 2009; SOUSA; BIANCHETTI, 2007; SEVERINO, 2006; SGUISSARD, 2006). Tal tendência tem implicações imediatas para as áreas com temáticas complexas como as de educação ambiental, que não podem prescindir de propostas criativas, muitas vezes diferenciadas e que envolvem diferentes áreas de conhecimento. Reigota (2009, p. 5) faz críticas rigorosas aos caminhos que temos apresentado aos novos pesquisadores quando os colocamos em confronto com "processos normativos, pragmáticos e produtivistas que dominam as universidades e que nos inflacionam com textos repetitivos, de originalidade duvidosa [...]".

Para além das questões relativas à concepção e às políticas de avaliação do sistema nacional de pós-graduação, vários autores chamam a atenção para a surpreendente diversidade em relação às áreas de conhecimento às quais os programas de pós-graduação que têm ancorado as pesquisas em EA estão vinculados. A equipe do Projeto EArte ${ }^{6}$ tem procurado compreender possíveis consequências ou decorrências desse vínculo institucional, via programas de pós-graduação, a áreas de conhecimentos tão diversas, para o processo de produção de conhecimento em EA. Tal diversidade envolve áreas do conhecimento não apenas com objetos distintos e próprios de investigação, mas também, e consequentemente, com perspectivas epistemológicas e teórico-metodológicas bastante diversificadas.

No texto no qual sintetizamos dados preliminares já sistematizados pela equipe EArte (CARVALHO et al. s/d, p. 14) ressaltamos o fato de que esse panorama, no contexto nacional, que evidencia essa multiplicidade de áreas de conhecimento às quais a pesquisa em EA se vincula, está em concordância com um dos mais evidentes consensos que temos construído, inclusive em nível internacional, qual seja, "a multiplicidade de áreas do conhecimento, disciplinas e tradições de investigação presentes no conjunto da produção da pesquisa em EA". Assim, desde os primeiros trabalhos que se voltam para a pesquisa em EA (p. ex. ROBOTTON; HART, 1993; HART; NOLAN, 1999) até o recente International Handbook of Research on Environmental Education (STEVENSON et al., 2013), essa é uma das características mais nomeadas e enfatizadas do campo.

O que nos interessa salientar, no entanto, é a riqueza do ponto de vista de possibilidades de pesquisa que esse cenário nos oferece. São diversas as possibilidades de

\footnotetext{
${ }^{6}$ Este projeto de pesquisa tem como objetivo organizar um banco de dados no qual as teses e dissertações em EA realizadas no Brasil são catalogadas, além de estudos analíticos dessa produção. A página eletrônica do projeto (www.earte.net) permite o acesso ao Banco de Dados de Teses e Dissertações e oferece uma visão panorâmica do projeto, incluindo alguns aspectos históricos, objetivos e os critérios de seleção e classificação dos trabalhos utilizados para a identificação e análise dos trabalhos incluídos no Banco de Dados.
} 
investigação que se abrem quando esses cenários são problematizados. O que estaria caracterizando a pesquisa em EA, nos seus diferentes aspectos, quando desenvolvida nesses diferentes espaços - não apenas do ponto de vista teórico-metodológico - mas também de habitus de produção de conhecimento?

\subsection{Pesquisa em EA e a Relação Público - Privado}

Outro aspecto que pode ser visto, também, como bastante significativo nos textos dos GDPs, quando buscamos delinear alguns indicadores em termos de demandas e agendas da pesquisa em EA, vincula-se à desejável articulação entre os diferentes espaços institucionais nos quais se desenvolvem as práticas educativas relacionadas com a temática ambiental. Assim, entende-se que a articulação entre os diferentes níveis dos espaços escolares e desses com os não escolares (ARAÚJO; MODESTO; SANTOS, 2016) ou a possibilidade de trazer para os espaços escolares a visão dos movimentos sociais (CAVALARI; TREIN, 2016) ampliam nossas perspectivas tanto em relação às práticas pedagógicas quanto em relação aos referenciais teóricos e metodológicos para nossas pesquisas.

Tais possibilidades de articulação entre esses diferentes espaços institucionais têm mobilizado, intensamente, os debates nos diferentes GDPs, apontando para questões de natureza diversa, todas elas, entretanto, instigantes se tomadas como problemas para investigação. Dentre essas diferentes possibilidades de articulação, destacamos a relação entre as diferentes instituições do setor público, principalmente as relações universidade-escolas da educação básica, as relações entre as instituições do setor público e o setor privado, de maneira especial, quando os textos dos GDPs nos remetem para as intricadas relações escolaempresas privadas e para as questões relativas ao financiamento público-privado da educação.

No que diz respeito às relações entre as universidades e as escolas da rede de educação básica, há o reconhecimento, em alguns dos textos dos GDPs, quanto à fragilidade das políticas de articulação mais efetivas entre esses níveis de ensino GUIMARÃES; QUEIROZ; PLÁCIDO, 2014); SILVA; GOMES, 2008; GUIDO; LIMA; CARVALHO, 2012). Ao mesmo tempo em que as universidades podem ser vistas como parceiras em processos que buscam a construção de novos padrões de relação entre as sociedades e entre essas e os outros elementos da natureza, as experiências de articulação concretas estão muito mais ligadas às iniciativas pontuais e isoladas do que à consecução de políticas mais efetivas nos diferentes níveis do poder público - municipal, estadual e federal - que garantam ações contínuas e de mais longo prazo. Assim, uma das alternativas levantadas por um dos grupos (LIMA; CARVALHO, 2014) aponta para o papel que as práticas de pesquisa poderiam cumprir na identificação, caracterização e divulgação de resultados de iniciativas das experiências concretas que têm sido desenvolvidas em parcerias dessa natureza.

São recorrentes nos GDPs a menção ao necessário retorno às escolas de educação básica dos resultados das pesquisas desenvolvidas nesses espaços institucionais pela Universidade. No entanto, o que me parece mais significativo é o reconhecimento de que as escolas da rede de educação básica não podem ser vistas como "espaços a serem analisados e estudados" (SILVA; GOMES, 2008, p. 254), enfim, vistas como laboratórios para experimentações ou fontes de problemas de investigação de interesse do mundo da academia. Ao contrário, o que se propõe como caminhos mais produtivos são projetos de pesquisa em colaboração, que se tornam, também, processos de formação contínua dos diferentes profissionais neles envolvidos, tendo como sustentação o diálogo entre os profissionais de ambos os espaços institucionais. $\mathrm{O}$ que se propõe são articulações que poderiam ser pensadas entre projetos político-pedagógicos das escolas de educação básica, com os projetos de investigação e de extensão universitária. Assim, os projetos de extensão universitária 
deixariam de ser vistos como ações extensionistas da universidade para as escolas e, sim, como ações colaborativas entre universidades e escolas, com o envolvimento dos diferentes profissionais em processos que têm como objetivos precípuos o ensino e a pesquisa.

Os textos dos GDPs são bastante férteis ao alimentar o acalorado debate sobre as atuais políticas de financiamento público da educação, de maneira geral, em especial dos processos de formação de professores. A constatação de que muito do financiamento público em educação está sendo direcionado para o setor privado, também chamado terceiro setor, compreendendo empresas, ONGs e OSCIPs, tem sido associada à incipiente articulação entre as universidades públicas e as escolas públicas da rede de educação básica. No entanto, em relação a esses processos, o que pode, muitas vezes, ser visto como causa, pode também ser associado às consequências das próprias políticas de financiamento.

No relato do GDP Pesquisa em EA e Questões Epistemológicas, do último EPEA, Cavalari e Trein (2016) chamam a atenção para a Conferência de Roberto Leher, quando esse pesquisador fez referência à perspectiva empresarial patente no programa "Todos pela Educação" e outras iniciativas do setor privado ${ }^{7}$. Segundo as autoras, chamados como esse, que apelam para que todos os setores sociais, indistintamente, se ocupem da educação, acabam por provocar "um processo de pasteurização das práticas educativas, com um caráter mais crítico, realizadas pelos educadores nas escolas de todo o país" (TREIN; CAVALARI, 2016, p. 84). Para essas autoras, as ações de controle para que o ideário que circunda iniciativas como essas se cumpra, "tais como medidas de desempenho, cumprimento de metas, realização de ações previstas em convênios com empresas; todas essas ações atravessam o currículo escolar e desarticulam o planejamento dos professores" (TREIN; CAVALARI, p. 84).

Como salientado no relato do GDP Pesquisa em EA em Contextos não Escolares, também no último EPEA, Saisse et al. (2016) explanam que projetos como esses, muito mais que pontuais ou meros fornecedores de materiais didáticos, influenciam decisivamente nas políticas educacionais e interferem nos projetos político-pedagógicos das escolas. Nessa mesma direção, Lima e Carvalho (2014, p. 149) registram o entendimento do GDP que se volta para contextos escolares de que tais movimentos "expropria[m] e proletariza[m] os docentes, que perdem o controle de sua produção curricular a partir de mecanismos de controle externos (formação do professor, apostilas etc.)".

Esse mesmo GDP, nas discussões realizadas em 2013, chama a atenção para o interesse que o projeto de "conversão das escolas em espaços educadores sustentáveis" vem despertando em empresas do setor privado e do terceiro setor, que buscam parcerias com governos estaduais e municipais para sua implementação (LIMA; CARVALHO, 2014, p. 151). Para alguns pesquisadores mencionados nesse texto, em boa medida, tais investidas têm origem nos processos de globalização da década de 1990, que apontam para a educação escolar como um caminho fundamental para o desenvolvimento econômico. Assim, as políticas públicas por meio de mecanismos como Leis de Incentivos Fiscais e programas de responsabilidade socioambiental têm incentivado a participação e, muitas vezes, intervenção do setor empresarial no sistema de educação público.

\footnotetext{
${ }^{7}$ Em seu texto, publicado neste número da Pesquisa em Educação Ambiental, Leher (2016, p. 14-15) não deixa dúvidas quanto aos efeitos das investidas do setor privado em relação às perspectivas postas pela EA crítica: "Com efeito, a incorporação nas diversas esferas do Estado, da agenda empresarial veiculada pelo Todos pela Educação, pela coalizão ultraconservadora Escola Sem Partido, pelas entidades sindicais patronais (Sistema S), pelas corporações (Vale S.A., Gerdau...) e pelas entidades empresariais do agronegócio (Associação Brasileira do Agronegócio), torna quase que estéril o solo para vicejar a educação ambiental inscrita na perspectiva histórico-crítica e libertária. O controle do capital sobre a educação básica busca pasteurizar, por meio de seu moinho triturador, todas as práticas educativas críticas nas escolas”.
} 
Diretamente relacionado com tais tendências em relação às políticas educacionais, principalmente as relacionadas com o financiamento da educação, as reflexões realizadas pelo GDP que tem como foco as políticas públicas, têm nos chamado a atenção para aspectos relativos à "gestão pública da Educação Ambiental e as questões de pesquisa que derivam das disputas travadas, tanto nas definições epistemológicas, quanto na materialidade das políticas públicas no contexto de reforma do Estado brasileiro" (SANTANA; LAMOSA, 2016, p. 108). Ao trazer essa questão para os debates, os pesquisadores participantes do GDP chamam a atenção para a necessária dimensão pública e participação da sociedade civil na elaboração das políticas públicas de educação e de educação ambiental, entendendo ser este um tema no qual se explicita um espaço político-pedagógico de conflito, que, ao demarcar e considerar os conflitos latentes, aposta nas possibilidades de construção de uma sociedade verdadeiramente democrática.

O papel da pesquisa e dos pesquisadores em EA passa, assim, a ser visto e anunciado no relato desse GDP como prática social que torna visível, pela mediação do conhecimento produzido, os interesses político-ideológicos implícitos nas políticas públicas. Segundo os autores, o pesquisador, ao assumir essa postura, desnaturaliza o Estado e as políticas públicas, identificando, nestes, as disputas, conflitos, negociações e consensos produzidos entre os agentes, coletivos e individuais, em luta (SANTANA; LAMOSA, 2016, p. 113).

\section{Considerações Finais}

Como inicialmente proposto, procuro retomar, neste texto, em grande parte, as questões que elegi como significativas e que me pareceram pertinentes para os debates dos quais participei na condição de convidado para compor a mesa redonda demandas e agendas da pesquisa em EA, ocorrida no VIII EPEA, em 2015.

O caminho que escolho para a registro de parte dessa trajetória é o de me pautar pelas experiências concretas de pesquisas já realizadas e pelos movimentos estratégicos da comunidade de pesquisadores para constituição do campo da Educação Ambiental, um campo que se constrói por meio de estratégias de consolidação/subversão, que nos dá sinais claros da existência de um grupo de pesquisadores que, ora aceita e ora subverte o jogo proposto, mas que encontra caminhos de sobrevivência salutar em meio a essa arena de lutas políticas próprias do campo científico em geral. Assim, procurei sistematizar, inicialmente, os movimentos da comunidade de pesquisadores em EA em nosso país e em outras regiões do mundo, que considero como estratégias de consolidação, conservação ou subversão desse campo do conhecimento.

O resultado dessa síntese, que aqui apresento, me aponta para uma realidade que se mostra instigante e digna de atenção e que, entendo, merece a atenção dos pesquisadores do campo e fornece elementos, também instigantes, para projetos na linha do estado da arte da pesquisa em EA. São várias e diversas as estratégias que vamos construindo para ocupar, de forma muitas vezes discreta, os diferentes espaços que se nos oferecem para divulgar e problematizar, a partir das questões postas pelo ideário ambientalista, as diferentes práticas e habitus desenvolvidos pelos diferentes campos de conhecimento em suas rotinas diárias de produção de conhecimento.

Diante de um campo que se constitui e se consolida a partir de ações rizomáticas, que se estendem pelos mais diversos espaços de construção de nossa realidade, a sensação de frustração diante da impotência em registrar parte dos complexos caminhos que vamos construindo, é inevitável. Tal sensação só pode ser atenuada quando nos convencemos que a possibilidade que se concretiza é a de contarmos apenas uma história. Aquela que podemos construir e contar a partir das experiências com as quais nos envolvemos mais de perto. 
Em um segundo momento do texto, retomo e complemento, a partir da leitura dos textos dos GDPs publicados em Pesquisa em Educação Ambiental, a reflexão iniciada quando de minha participação na mesa redonda acima referida procurando, nesse processo que assumo como um elo na cadeia de produção de sentidos sobre o campo da investigação em EA, apontar para possíveis demandas e agendas de pesquisa para esse campo.

Procuro fazer esse exercício, não, necessariamente, a partir de uma hierarquização ou juízos de valor quanto ao significado dos aspectos que escolho para aqui sistematizar. Nesse sentido, como já anteriormente mencionado, faço escolhas. As escolhas que fiz privilegiaram, inicialmente, a busca nesses textos por elementos que me permitissem aprofundar os aspectos que já haviam sido apontados como significativos em termos de demandas e agendas, quando de minha intervenção na mesa redonda do VIII EPEA. Sendo assim, os aspectos que aqui levanto não necessariamente são trazidos para o texto a partir de juízos de valor em relação aos diferentes aspectos levantados nos relatos dos GDPs. Para além das escolhas que fiz quando de minhas reflexões para o desenvolvimento dos trabalhos junto à mesa-redonda, considero, também, ora a reincidência desses aspectos levantados em diferentes GDPs, ora as ênfases postas pelos autores e pelo próprio grupo nas questões sistematizadas no texto, ora, as possíveis associações dos resultados dos trabalhos dos grupos com aspectos que têm sido enfatizados em outras experiências que tenho tido com o campo da pesquisa em EA.

De qualquer forma, as demandas e agendas que escolhi trazer para o texto não esgotam exercícios como este a que me propus e para os quais estou sempre motivado, mas que, espero, sobretudo, motivem também outros pesquisadores nesse processo de tentativas de apontar para aspectos significativos e que mereçam nossa atenção como pesquisadores.

Esse me parece ser um caminho saudável e plausível para que essa corrente infinita de enunciados nos permita aproximações com uma postura dialógica constante sobre o campo da pesquisa em EA, de tal forma, que nossas práticas discursivas sobre esse campo possam refletir e dialogar, de forma mais ampla, com o campo da educação e com o campo ambiental.

\section{Referências}

ARAÚJO, M. I. O.; MODESTO, M. A.; SANTOS, T. F. Caminhos e dilemas da educação ambiental no contexto escolar. Pesquisa em Educação Ambiental, São Carlos, vol.11, n.2 p. 129-136, dez. 2016.

BAKHTIN, M. M. Estética da Criação Verbal. 6. ed. São Paulo: WMF Martins Fontes, 2010.

BAKHTIN, M. M.; VOLOSHINOV, V. N. Marxismo e Filosofia da Linguagem. São Paulo: Hucitec, 2009.

BOURDIEU, P. O campo científico. In: ORTIZ, R. (Org.). Pierre Bourdieu: Sociologia. São Paulo: Editora Ática, 1983. p. 122-155.

BOURDIEU, P. Os usos sociais da Ciência: por uma clínica do campo científico. São Paulo: EdUNESP, 2004.

CAMARGO, T. D’A.; TONSO, S. Educação Ambiental crítica e epistemologia do Sul: reflexões sobre o "vivirbien" (Suma Qamaña) In: ENCONTRO DE PESQUISA EM EDUCAÇÃO AMBIENTAL, 7, 2013, Rio Claro. Anais... Rio Claro: Instituto de Biociências, 2013. p. 1 - 16. Disponível em: <http://www.epea.tmp.br/epea2013_anais/pdfs/plenary/0211-1.pdf〉. Acesso em: 10 jan. 2017.

CARVALHO, I. C. M. A configuração do campo da pesquisa em educação ambiental: considerações 
sobre nossos autorretratos. Pesquisa em Educação Ambiental, São Carlos, v. 4, n. 2, p. 127-134, dez. 2009.

CARVALHO, L. M. A Temática ambiental e a Escola de $1^{\circ}$ Grau. 1989. 282f. Tese (Doutorado em Educação) - Universidade de São Paulo, São Paulo, 1989.

CARVALHO, L. M. Que Educação Ambiental desejamos? Revista Ciências em Foco, Campinas, v. 1, n. 3, p. 1-22, 2010.

Carvalho, L. M. Pesquisa em Educação Ambiental no Brasil: um campo em construção? 2016. 458p. (Tese de Livre-Docência). Universidade Estadual Paulista "Júlio de Mesquita Filho", Rio Claro, 2016.

CARVALHO, L. M. et al. Environmental Education (EE) Research in Brazil: some highlights from theses and dissertations. (s/d; em preparação).

CARVAlHO, L. M.; TOMAZELlO, M. O.; OlIVEIRA, H. Pesquisa em Educação Ambiental: panorama da produção brasileira e seus dilemas. Cadernos Cedes, Campinas, v. 29, n. 77, p.13-27, jan./abr. 2009.

CARVALHO, L. M.; KAWASAKI, C. S. Um panorama do estado da arte da pesquisa em Educação ambiental no Brasil. IN: ESCHENHAGEN, M. L.; CUARTAS, G. V.; MALDONADO, C. La Producción de Conocimiento em la Universidad: metodologias y políticas de investigación. Medellín: Editora da Universidad de Antioquia (no prelo).

CAVALARI, R. M. F.; SANTANA, L. C.; CARVALHO, L. M. Concepções de educação e Educação Ambiental nos trabalhos do I EPEA. Pesquisa em Educação Ambiental, São Carlos, v. 1, n. 1, p. 141173, jul. 2006.

CAVALARI, R. M. F.; TREIN, E. Pesquisa em Educação Ambiental e questões epistemológicas: a necessidade da continuidade do debate. Pesquisa em Educação Ambiental, São Carlos, v.11, n. 2, p. 83-96, dez. 2016.

COSTA, C. A. Interculturalidade, exclusão e libertação em Paulo Freire na leitura de Enrique Dussel: aproximações para a pesquisa em educação ambiental crítica. In: ENCONTRO DE PESQUISA EM EDUCAÇÃO AMBIENTAL, 8, 2016, Rio de Janeiro. Anais.... Rio de Janeiro: Unirio, 2016. p.1-15. Disponível em: <http://epea.tmp.br/epea2015_anais/pdfs/plenary/3.pdf>. Acesso em: 10 jan. 2017.

FLORIANI, D. Educação Ambiental e epistemologia: conhecimento e prática de fronteira ou uma disciplina a mais? Pesquisa em Educação Ambiental, São Carlos, v.4, n. 2, p. 191-202, dez. 2009.

FRACALANZA, H. As pesquisas sobre educação ambiental no Brasil e as escolas: alguns comentários preliminares. In: TAGLIEBER, J.E.; GUERRA, A.F.S. (Orgs.). Pesquisa em educação ambiental: pensamentos e reflexões de pesquisadores em educação ambiental. Pelotas: Universitária, 2004. p. 55-77.

FRACALANZA, H. et al. A educação ambiental no Brasil: panorama inicial da produção acadêmica. In: ENCONTRO NACIONAL DE PESQUISA EM EDUCAÇÃO EM CIÊNCIAS, 5, 2005, Bauru. Anais... Bauru: ABRAPEC, 2005. p. 1-12. Disponível em: <http://www.nutes.ufrj.br/abrapec/venpec/conteudo/artigos/3/pdf/p272.pdf>. Acesso em: 27 nov. 2015 .

FREITAS, D.; OLIVEIRA, H. T. Pesquisa em Educação Ambiental: um panorama de suas tendências metodológicas. Pesquisa em Educação Ambiental, Rio Claro, v. 1, n. 1, p. 175-191, jul. 2006. 
GATTI, B. Implicações e perspectivas da pesquisa educacional no Brasil contemporâneo. Cadernos de Pesquisa, São Paulo, s/v, n. 113, p. 65-81, jul. 2001.

GATTI, B. A. Estudos quantitativos em educação. Educação e Pesquisa, São Paulo, v. 30, n. 1, p. 1130, jan./abr. 2004.

GOERGEN, P. Teoria e ação no GT Educação Ambiental da ANPED: partilhando algumas suspeitas epistemológicas. Pesquisa em Educação Ambiental, São Carlos, v. 5, n. 2, p. 9-30, dez. 2010.

GOUGH, S. Editorial. Environmental Education Research, Bath, v. 10, n.1, p. 3-6, dez. 2004.

GOUGH, A. Historical, contextual, and theoretical orientations that have shaped environmental education research: introduction. In: STEVENSON, R. et al. (Ed.) International handbook of research on Environmental Education. New York/London: AERA/Routledge, 2013a. p. 09-12.

GOUGH, A. The emergence of Environmental Education research: a "history" to the field. In: STEVENSON, R. et al. (Ed.). International handbook of research on Environmental Education. New York/London: AERA/Routledge, 2013b. p. 13-22.

GUIDO, L. F. E.; LIMA, J. G. S.; CARVALHO, L. M. Pesquisa em Educação Ambiental no contexto escolar: considerações a partir do grupo de discussão de pesquisa. Pesquisa em Educação Ambiental, São Carlos, v. 7, n. 2, p. 105-118, dez. 2012

GUIMARÃES, M.; QUEIROZ, E. D.; PLÁCIDO, P. Reflexões sobre a pesquisa na formação de professores, Pesquisa em Educação Ambiental, Rio de Janeiro, v. 9, n. 1, p. 110-119, jul. 2014.

HART, P.; NOLAN, K. A critical analysis of Research in environmental education. Studies in Science Education, Leeds, v. 34, n. 1, p. 1-69, 1999.

HIGUCHI, M. I.; MAROTI, P. S. Espacialidades e socialidades da educação ambiental além dos muros da escola. Pesquisa em Educação Ambiental, São Carlos, v. 9, n. 1, p. 95-109, jul. 2014.

HIGUCHI; M. I. G; MOREIRA JR. W. Educação Ambiental e movimentos sociais: espaços paralelos ou compartilhados? Pesquisa em Educação Ambiental, São Carlos, v. 4, n. 2, p. 165-174,dez. 2009.

HIGUCHI, M. I.; ZATTONI, M.; BUENO, F. P. Educação ambiental em contextos não escolares: definindo, problematizando e exemplificando. Pesquisa em Educação Ambiental, São Carlos, v. 7, n. 2, p. 119-132, dez. 2012.

JOURNAL OF ENVIRONMENTAL EDUCATION (JEE). Taylor \& Francis Newspaper Online Portal. Disponível em: <http://www.tandfonline.com/toc/vjee20/current>. Acesso em: 10 jan. 2017.

LAYRARGUES, P. P.; LIMA, G. F. C. As macrotendências político-pedagógicas da Educação Ambiental brasileira. Ambiente \& Sociedade, São Paulo, v. 17, n. 1, p. 23-40, jan./mar. 2014.

LEFF, H. Epistemologia Ambiental. São Paulo: Cortez, 2002.

LIMA, J. G. S. L; CARVALHO, L. M. 2014. Educação Ambiental e contexto escolar: questões para um programa de pesquisas. Pesquisa em Educação Ambiental, São Carlos, v. 9, n. 1, p. 144-155, jul. 2014. 
LORENZETTI, L. Estilos de Pensamento em Educação Ambiental: uma análise a partir das teses e dissertações. 2008. 406 f. Tese (Doutorado em Educação Científica e Tecnológica) - Universidade Federal de Santa Catarina, Florianópolis, 2008.

LOUREIRO, C. F. B. Educação Ambiental transformadora. In: LAYRARGUES, P. P. (Coord.). Identidades da Educação Ambiental Brasileira. Brasília: Ministério do Meio Ambiente, 2004. p. 6584.

LOUREIRO, C. F. B. Educação Ambiental e Movimentos Sociais: reflexões e questões levantadas no GDP. Pesquisa em Educação Ambiental, São Carlos, v. 3, n. 1, p. 187-201, jan./jun. 2008.

MOLON, S. I. Formação em Educação Ambiental: um olhar sobre o PPGEA/FURG. Revista Eletrônica do Mestrado em Educação Ambiental, v. Especial, s/n, p. 71-86, dez. 2008.

MOREIRA, A. F. A cultura da performatividade e a avaliação da pós-graduação em educação no Brasil. Educação em Revista, Belo Horizonte, v. 25, n. 3, p. 23-42, nov. 2009.

PATO, C.; SÁ, L. M.; CATALÃO, V. L. Mapeamento de tendências na produção acadêmica sobre Educação Ambiental. Educação em Revista, Belo Horizonte, v. 25, n. 3, p. 213-224, dez. 2009.

PAYNE, P. G. Framing research: conceptualizing, contextualizing, representation, legitimization. Pesquisa em Educação Ambiental, São Carlos, v. 4, n. 2, p. 49-77, dez. 2009.

REID, A.; SCOTT, W. Identifying needs in Environmental Education Research. In: STEVENSON, R. et al. (Ed.). International handbook of research on Environmental Education. New York/London: AERA/Routledge, 2013. p. 518-528.

REIGOTA, M. Educação Ambiental brasileira: a contribuição da nova geração de pesquisadores e pesquisadoras. Interacções, Lisboa, s/v, n. 11, p. 1-7, 2009.

REIGOTA, M. Educação Ambiental: a emergência de um campo científico. Perspectiva, Florianópolis, v. 30, n. 2, p. 499-520, mai./ ago. 2012.

ROBOTTON, I.; HART, P. Research in Environmental Education: engaging the debate. Geelong: Deakin University, 1993.

SAISSE, M. V.; OLIVEIRA, H. T.; DORNFELD, C. B.; AMARAL, A. Q. 2016. Pesquisa em educação ambiental em contextos não escolares: pertinência do recorte e interfaces entre os grupos de discussão dos encontros de pesquisa em educação ambiental (EPEA's). Pesquisa em Educação Ambiental, São Carlos, v. 11, n. 2, p. 134-145, dez. 2016.

SANTANA, L. C.; LAMOSA, R. A. C. Pesquisa em Educação Ambiental e políticas públicas: desafios políticos e epistemológicos. Pesquisa em Educação Ambiental, São Carlos, v. 11, n. 2, p. 105-116, dez. 2016.

SEVERINO, A. J. A avaliação no PNPG 2005-2010 e a política de pós-graduação no Brasil. In: FERREIRA, N.S.C. (Org.). Políticas públicas e gestão da educação: polêmicas, fundamentos e análises. Brasília: Líber Livro, 2006.

SGUISSARD, V. A avaliação defensiva no "modelo CAPES de avaliação" - É possível conciliar avaliação educativa com processos de regulação e controle do Estado? Perspectiva, Florianópolis, v. 24, n. 1, p. 49-88, jan./jun. 2006. 
SILVA, L. F.; GOMES, M. M. A pesquisa em Educação Ambiental no contexto escolar: contribuições para uma reflexão. Pesquisa em Educação Ambiental, São Carlos, v. 3, n. 1, p. 239-256, jul. 2008.

SOUSA, S. Z.; BIANCHETTI, L. Pós-graduação e pesquisa em educação no Brasil: o protagonismo da ANPED. Revista Brasileira de Educação, Rio de Janeiro, v. 12, n. 36, p. 389-409, set./dez. 2007.

STEVENSON, R. et al. International handbook of research on Environmental Education. New York/London: AERA/Routledge, 2013.

TOZONI-REIS, M. F. C. Educação Ambiental: natureza, razão e história. 2. ed. Campinas: Autores Associados, 2008.

TOZONI-REIS, M. F.; SOUZA, D. C. Pesquisa em Educação Ambiental e questões metodológicas: uma discussão coletiva. Pesquisa em Educação Ambiental, São Carlos, v. 9, n. 1, p. 133-143, jul. 2014.

TREIN, E.; CAVALARI, R. M. F. A pesquisa em Educação Ambiental e questões epistemológicas: a permanência e a renovação. Pesquisa em Educação Ambiental, São Carlos, v. 9, n. 1, p. 120-132, jul. 2014.

TREIN, E. S. A Educação Ambiental Crítica: crítica de quê? Revista Contemporânea de Educação, Rio de Janeiro, v. 7, n. 14, p. 304-318, ago./dez. 2012. 